REVISTA ARA N7 . VOLUME 7 . PRIMAVERA+VERÃO 2019 • GRUPO MUSEU/PATRIMÔNIO FAU-USP

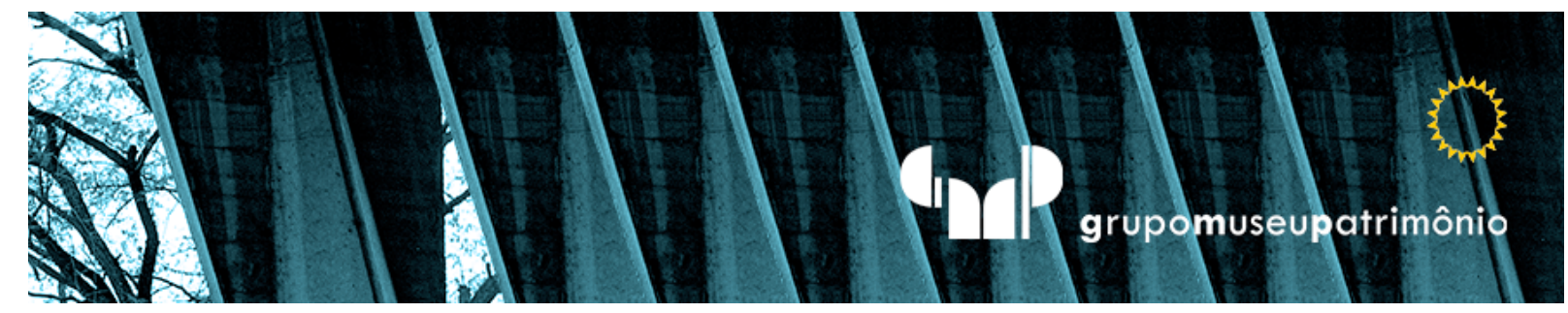

\title{
O olhar de Giorgio Agamben sobre as Ninfas
}

\author{
El ver de Giorgio Agamben a las Ninfas
}

\section{The look of Giorgio Agamben on the Ninfas}

\section{Anna Maria Rahme}

Pesquisadora no Grupo Museu/Patrimônio da Faculdade de Arquitetura e Urbanismo da USP, São Paulo, Brasil. annarahme@gmail.com 


\section{Resumo}

O texto propõe uma análise do livro Ninfas, 2007, de Giorgio Agamben, no qual o autor se apropria da figura mítica da ninfa e recompõe a história da humanidade, pelos fantasmas e imagens, abordando os conceitos de natureza, mito, reprodução, recepção, memória, movimento, renovação, vida, tempo, signo, imaginação. A resenha crítica mantém o foco sobre os diálogos que Agamben promove com diferentes pensadores e artistas, mas fundamentalmente com o pesquisador Aby Warburg e o filósofo Walter Benjamin.

Palavras-Chave: Ninfa. Imagem. Repetição. Memória. Tempo.

\section{Resumen}

El texto propone un análisis del libro Ninfas, 2007, de Giorgio Agamben, en el que el autor se apropia de la figura mítica de la ninfa y recompone la historia de la humanidad, por los fantasmas y las imágenes, abordando los conceptos de naturaleza, mito, reproducción, recepción, memoria, movimiento, renovación, vida, tiempo, signo, imaginación. La crítica mantiene el enfoque en los diálogos que Agamben promueve con diferentes pensadores y artistas, pero fundamentalmente con el investigador Aby Warburg y el filósofo Walter Benjamin.

Palavras-Clave: Ninfa. Imagen. Repetición. Memoria. Tiempo.

\section{Abstract}

The text proposes an analysis of the book Ninfas, 2007, by Giorgio Agamben, in which the author appropriates the mythical figure of the nymphin and recomposes the history of mankind, by the ghosts and the images, addressing the concepts of nature, myth, reproduction, reception, memory, movement, renewal, life, time, sign, imagination. The critical review maintains the focus on the dialogues that Agamben promotes with different thinkers and artists, but fundamentally with the researcher Aby Warburg and the philosopher Walter Benjamin.

Keywords: Nymph. Image. Repetition. Memory. Time. 


\section{INTRODUÇÃO ${ }^{1}$}

A história da relação ambígua entre os homens e as ninfas é a história da difícil relação entre o homem e as imagens. Giorgio Agamben (2010, p.44).

ssas palavras de Giorgio Agamben finalizam a exposição dos motivos da escolha da figura mitológica das Ninfas $^{2}$, fundamentalmente, focando nos estudos de Aby Warburg (1866-1929), com o intuito de comprovar a tese de que é o contato com os homens que dá vida a esses seres inanimados. O autor se dedica a recompor a história da humanidade, pelos fantasmas e imagens, e aponta a responsabilidade da imaginação na "tarefa de sua dialética recomposição" (2010, p. 53). Filósofo da atualidade, Agamben adota a atemporalidade como

\footnotetext{
${ }^{1} \mathrm{O}$ texto escolhido, agora transformado em resenha, foi apresentado em Ago. 2019 dentro da atividade Seminários Regulares do Grupo Museu/Patrimônio, FAUUSP.

${ }^{2}$ Ninfas foi publicado pela primeira vez em 2007 - Ninfe, em italiano, língua original de Giorgio Agamben -e, portanto, três anos antes da versão aqui apontada, em espanhol. Todas as citações têm tradução livre da autora. Igualmente, é de responsabilidade da autora o uso de negritos para algumas palavras no decorrer dos parágrafos, cuja finalidade foi alertar para termos significativos no processo de análise.
} 
procedimento, destituindo sacralidades e mitos, por atitudes que denomina "profanações" ${ }^{3}$ e que permeiam grande parte de suas idéias.

A partir do conceito de contemporâneo, formulado por Agamben, não como um momento mas como a potência de transformação refletindo o processo da vida, pode-se perceber o engajamento, do estudo dos gestos e sua permanência, no tema da publicação ARA 7 Horizontes extremos: desafios ou fronteiras. No texto em questão, ele explora pesquisas teóricas e/ou iconográficas marcantes de diferentes artistas e pensadores, desde o século XIV até o século XXI. Inclui, entre outros: Giovanni Boccaccio (1313-1375), Domenico de Piacenza (1390-1470), Paracelso (1493-1541), André Jolles (18741946), Walter Benjamin (1892-1940), Henry Darger (1892-1973), Theodor Adorno (1903-1969), Bill Viola (1951).

Para compreender o apelo da filosofia moderna às Ninfas, é preciso conhecer sua origem, os atributos e o papel desempenhado na Teogonia grega, aparecendo pela primeira vez em poemas de Hesíodo ${ }^{4}$, por volta de 700 a.C. Para ele, essas criaturas "estão entre as divindades primordiais do cosmos e, como filhas da Terra, associadas aos estratos mais antigos da história da religião grega" (Krausz, 2007, p. 97), e os lugares onde se manifestavam eram tidos como sagrados porque "a concepção panteísta do universo via epifanias nas paisagens, no fenômeno de um mundo impregnado de essências divinas" (2007, p. 97).

Material arqueológico e literário comprova a ampla difusão e popularização do culto a essas filhas de Zeus ${ }^{5}$, bem como sua ligação com a fertilidade, ao parto

\footnotetext{
${ }^{3}$ Sob o título Profanações (2004) Giorgio Agamben reuniu em livro, pela Editora Boitempo, temas como: Magia e Felicidade, Paródia, Desejar, O Ser Especial, O Autor como Gesto

4 “Hesíodo é o primeiro dos poetas gregos a apresentar um relato pessoal de sua iniciação ao mundo e à arte das Musas" (Krausz, 2007, p. 95).

${ }^{5}$ No capítulo Iniciação do livro As Musas, Luís S. Krausz esclarece que para Hesíodo - um pastor que vivia no Monte Hélicon e lá, num encontro direto com as Musas, teria se tornado poeta, cantando coisas do presente, do passado e do futuro - as Ninfas se confundem com as Musas e ambas são filhas de Zeus. Essa crença é corroborada por diferentes profetas e poetas gregos, sendo emblemático o caso da Odisseia na qual em momentos distintos surgem oferendas feitas
} 
e à mortalidade infantil. Poderes terríveis também são atribuídos às Ninfas, "um lado sombrio e vingativo é a contrapartida do encantamento positivo proporcionado pela sua presença" (Krausz, 2007, p. 102), sedução e loucura, esta última como um transe temporário ou permanente. Essas crenças estão na Teogonia de Hesíodo e fazem parte da religião popular, ligada à vida e à cultura dos camponeses, e se opõe ao panteão da "épica homérica, com suas divindades de atributos bem delimitados e específicos" (2007, p. 103).

É importante recordar que na cosmogonia arcaica as Musas são consideradas filhas de Zeus e Mnemosine - que possui poderes titânicos -, enquanto na Teogonia, de Hesíodo, a Memória é irmã de divindades influentes e a ela se atribui a preservação de tudo o que aconteceu ao longo do tempo (Krausz, 2007 , p. 19). Os temas míticos são apresentados em forma de poesia épica, que revelam à humanidade o conhecimento de todo o passado - reatualizado e recriado a cada vez que é rememorado pelo poeta - e tornam-se a única maneira de "escapar do esquecimento e, portanto, para conquistar uma certa forma de imortalidade, que é a de existir para sempre, para além da morte, na memória" (2007, p. 25).

\section{Enfoque conceitual}

É, no mínimo, intrigante observar o fio condutor do qual Agamben lança mão, a partir da exposição Passions ${ }^{6}$, 2003, com vídeos de Bill Viola no Getty Museum de Los Angeles, com imagens de "telas de antigos mestres" (2010, p. 10) imóveis, mas que lentamente se animavam e suscitavam no espectador simultaneamente a "impressão de familiaridade e estranhamento" (2010, p.

às Ninfas náiades, como aquela de Ulisses numa caverna junto ao porto de Fórcis ou a de Eumeu num altar em Ítaca (Idem, p. 93-109).

${ }^{6}$ Bill Viola conta que a série de vídeos Passions tem origem nos estudos realizados sobre peças da pintura medieval e a percepção dos gestos não explícitos dos atores, mas que certamente se revelam àquele fruidor mais atento. É, justamente, em busca desse momento que o artista reconstitui as cenas das obras, usando atores da atualidade, em movimentos muito lentos e filmagens em slow motion, que demandam maior tempo de observação e obrigam o olhar a se deter e, portanto, perceber novos gestos intermediários - que se revelam no processo - antes de visualizar a cena final. 
10). Descreve a recepção da obra como a conversão do musée imaginaire em musée cinématographique e logo recorre a Benjamin e suas pesquisas sobre a necessidade de uma maior atenção para a fruição de uma reprodução. Introduz o tempo como dimensão da vida, descartando o movimento, ao falar da imersão nos vídeos que "não inscrevem as imagens no tempo, mas o tempo nas imagens" (2010, p. 11).

Ainda, tendo como foco a relação entre o tempo e as imagens Agamben estuda o tratado De la arte di ballare et danzare, escrito pelo coreógrafo e professor de dança Domenico de Piacenza em meados do século XV, no qual são enumerados seis elementos fundamentais da arte: medida, memória, agilidade, maneira, espaço e fantasmata sendo este último "absolutamente central" (2010, p. 13) por incorporar "tantas coisas que não se pode dizer" (2010, p. 14), seja por indicar presteza corporal (determinada pela medida), seja pelo apelo à memória ou o cálculo do espaço e do ar. Apregoa o "dançar por fantasmata" (2010, p. 15), "detendo-se no momento em que pareça visualizar a cabeça da Medusa" (2010, p. 15). O corpo e seu movimento não é o verdadeiro lugar do bailarino para Domenico, mas "na imagem da 'cabeça da Medusa', como pausa na imobilidade [...] de memória e de energia dinâmica. Isto significa que a essência da dança não é o movimento, é o tempo" (2010, p.15).

Apontando a probabilidade de Aby Warburg ter conhecido o tratado de Domenico, quando de seus estudos em Florença, Agamben fala da semelhança de "visão da imagem como Pathosformel do 'fantasmata' que condensa em uma brusca parada a energia do movimento e da memória" (2010, p. 17). Pathosformel (1905) é usado por Warburg no lugar de Pathosform (fórmula de pathos), "sublinhando o aspecto estereotipado e repetitivo do tema imagético com o qual o artista é mediado a todo momento para expressar a 'vida em movimento'" (2010, p. 17-8). Os gestos - expressividade do corpo - com origem nas paixões e afeições humanas ganham forma e polarizam-se invertendo significados. As soluções "são híbridas de matéria e forma, de criação e performance, de originalidade e repetição" (2010, p. 18) e, portanto, têm comportamento dialético. 
Esses conceitos têm origem, em 1923, com as pesquisas de Warburg sobre os gestos carregados de um pathos da linguagem mímica nas representações da Antiguidade no Renascimento e, em especial, duas pinturas de Sandro Botticelli (1445-1510), O nascimento de Vênus (1486) e A Primavera (1482). Nelas observa um regresso das formas pela a repetição, como sintomas que manifestam um mecanismo inconsciente da memória cultural pelas sobrevivências primitivas. Tais estudos serão fundamentais para a montagem do Atlas Minemosyne ${ }^{7}$, um arquivo da memória constituído de 63 painéis com cerca de mil fotografias em montagem sincrônica, com o qual buscou permanências e comprovar similaridades.

Sem dúvida, tal processo de circulação das formas expressivas fundamentou as análises de Walter Benjamin para a obra "Teses sobre o conceito de história" (1940), que examina a função da memória social da humanidade baseado na "teoria da memória social ou coletiva". Da mesma maneira, Benjamin compõe A obra de arte na era de sua reprodutibilidade técnica (1936) pensando positivamente na atrofia da aura $^{8}$ e na distribuição em massa ${ }^{9}$ advinda da multiplicação do objeto de arte em tempos de reprodução técnica. Resumindo, ele escreve que "a autenticidade de uma coisa é a cifra de tudo o que desde a origem pode transmitir-se nela, de sua duração até seu testemunho histórico" (Benjamin, 1989, p.22).

${ }^{7}$ O Atlas Mnemosyne, exposto na entrada da Biblioteca do Instituto Warburg só foi publicado após a morte, c. 1932. Esses arquivos ficaram conhecidos por respaldarem estudos de importantes pesquisadores: E. Gombrich (dirigiu o Instituto em 1952 e publicou a biografia de Warburg); I. Panofsky (dando fundamentos para seu livro Perspectiva como forma simbólica); E. Cassirrer (idem para A filosofia das formas simbólicas).

${ }^{8} \mathrm{E}$, ainda, sobre a destituição da aura pela reprodução técnica, Benjamin diz que "pela primeira vez na história universal, a reprodutibilidade técnica, em um ritual, emancipa a obra de arte de sua existência parasitaria" (1989, p.27).

${ }^{9} \mathrm{~S}$ orientação da realidade às massas e destas à realidade é um processo de alcance ilimitado tanto para o pensamento quanto para a contemplação" $(1989$, p.25). 


\section{Antiguidade e ritualização, Modernidade e dialética}

Certamente, os estudos de Warburg e a construção do seu Atlas Mnemosyne orientaram o olhar de Benjamin e Agamben, para a importância da duração das imagens na construção da história, visto que a transmissão da imagens por gerações é uma operação de renovação, porque coloca o passado em movimento e abre novas possibilidades. Parece ser este o foco de Agamben quando analisa o repertório de modelos e gestos - variações seriais de uma Pathosformel - tanto nos afrescos de Guirlandaio (1449-1494) na igreja Santa Maria Novella, como nas colagens feitas no século XX por Henry Darger (18921973), em Chicago.

Em relação às recorrentes e distintas imagens femininas figuradas nas obras florentinas das últimas décadas do século XV o autor se pergunta, onde está a ninfa, já que "[...] a ninfa não é a matéria à qual o artista deva conferir nova forma, nem um molde para ajustar os próprios materiais emocionais" (Agamben, 2010, p.19). Acrescenta, ainda, que dadas a incompreensível originalidade e a repetição da ninfa, trata-se de um ser cuja "forma coincide precisamente com a matéria e cuja origem é um inexplicável tornar-se aquilo que chamamos de tempo, que Kant definia por isto como auto contaminação" (2010, p. 19).

Sobre a coleção de peças de Darger ${ }^{10}$ - colagens a partir de recortes e decalques, ampliados ou in natura, de garotas de álbuns de desenhos em quadrinhos e periódicos - Agamben fala que esta foi a maneira escolhida para compor artisticamente a Pathosformel com um extraordinário poder de modernidade. Aqui, a transmissão da história se dá pela restituição da vida às imagens fixadas em espectros, imagens feitas "de tempo e de memória" (2010,

\footnotetext{
${ }^{10}$ Quando faleceu Henry Darger, ilustrador em Chicago, Nathan Lerner - fotógrafo e designer novaiorquino, proprietário da casa onde Darger vivera por quarenta anos - deparou-se com um amontoado de objetos de todo tipo entre os quais encontrou um verdadeiro legado contendo quinze volumes manualmente encadernados, quase trinta mil páginas, sobre a história de sete ninfas: In the Realms of the Unreal. (Agamben, 2010, p.21)
} 
p. 23), criando um processo interminável - passível de ter continuada sua construção -, calcado na proposta científica de Warburg (2010, p. 23).

$E$, lembrando da proximidade temporal entre as pesquisas desse cientista e o nascimento do cinema, Agamben é levado a traçar uma ligação entre vida e movimento, alegando o aproveitamento do "material cinético e presente na imagem - fotograma isolado, o Pathosformel mnético - e que está em ralação com aquilo que Warburg definia com o termo Nacheleben, vida póstuma (ou sobrevivência)" (2010, p. 25). Entenda-se, por vida póstuma, além do efeito fisiológico da persistência retiniana da imagem o efeito mnético, ou seja, “há um Nacheleben histórico", "que as constitui como 'dinamogramas'” (2010, p. 26). Mais que um efeito, portanto, é "uma operação, cuja execução corresponde ao sujeito histórico" (2010, p. 27) e, por meio dela o passado, que parecia estar encerrado e inacessível, se coloca em movimento

Benjamin reitera essa análise quando fala do movimento das câmeras cinematográficas: "Por sua virtude experimentamos o inconsciente ótico, semelhante ao que se passa por meio da psicanálise, nos inteiramos do inconsciente pulsional" (1989, p.48). Tais afirmações corroboram o pensamento do filósofo a respeito de que a reprodutibilidade técnica da obra de arte redunda em secularização do valor cultual da imagem e, consequentemente, em representar "com maior indeterminação o substrato de sua singularidade" gerando uma emancipação de "sua existência parasitária em um ritual" (1989, p. 26). Assim, "em vez de sua fundamentação em um ritual aparece sua fundamentação em uma praxis distinta, a saber na política" (1989, p. 27), respaldando sua teoria do conhecimento histórico.

Quando trabalha no livro Passagens de Paris (1919), Walter Benjamin elabora o conceito de imagem dialética na qual "a verdade se apresenta historicamente como 'morte da intenção"' (Agamben, 2010, p. 29) e lhe confere "uma dignidade 
comparável aos eide da fenomenologia ${ }^{11}$ e às ideias de Platão" (2010, p. 29). “O movimento dialético que é captado no ato de sua suspensão" (2010, p. 29) define as imagens como a união do que foi com o agora, numa constelação saturada de tensões. Em 1935, Theodor Adorno (1903-1969) se debruça sobre tais ideias, focando especialmente sobre o "esvaziamento do significado operado nos objetos pela intenção alegórica" (2010, p. 30) que reforça as acepções subjetivas que introduzem intenções de desejo e de angustia. Críticas refutadas por Benjamin, com a defesa de que a imagem dialética é "uma oscilação não resultante entre a saudade e um novo acontecimento do sentido" e por isso mesmo ambíguo segundo Adorno (2010, p. 31).

Agamben explica que os embates acontecem devido às distintas linhas de pensamento entre eles, já que Benjamin se refere a "uma concepção da dialética cujo mecanismo não é lógico (como em Hegel), mas analógico e paradigmático (como em Platão)" (2010, p. 32), cujos termos "não são suprimidos nem constituídos em unidade, mas que se mantêm numa coexistência imóvel e carregada de tensões" (2010, p. 32). Esta "dialética em estado de tensão" tem sua origem com Aristóteles ${ }^{12}$ e, segundo Benjamin, é "capaz de relacionar um instante do passado com o presente" na imobilização brusca do pensamento (2010, p. 33).

\section{Memória e signo}

Para abordar a questão simbólica ligada à imagem, Giorgio Agamben introduz o conceito de esvaziamento do sentido mítico originário no decorrer do

\footnotetext{
${ }^{11}$ Pelo Dicionário de Filosofia, na Fenomenologia de Husserl, a redução é um dos procedimentos centrais do método fenomenológico, significando que deve se concentrar a atenção nas coisas mesmas e não nas teorias. A redução eidética é o passo seguinte nesse procedimento, fazendo com que se visem as essências e não os objetos concretos. Por fim, a redução transcendental se dá quando a consciência engloba as essências e os objetos considerando-os como fenômenos.

${ }^{12}$ Em Segundos analíticos, Aristóteles compara o estancar do pensamento em que se produz o universal - gerado analogicamente e não por procedimento indutivo - à reconstituição da composição inicial de um exército em fuga que tenha se desorganizado após a parada repentina de um de seus membros, depois mais um e assim por diante. (Agamben, 2010, p. 32)
} 
tempo e o fato de que "o observador não crê mais na força mágico-religiosa das imagens, mesmo assim, as mantém em suspenso entre o ícone eficaz e o signo puramente conceitual" (2010, p. 36), entre o mito e a razão. Assinala a centralidade das imagens entre dois polos opostos do ser humano, não como um ponto médio, mas como algo imóvel para um ser de passagem, algo como o "fantasmata" de Domenico, a operação do Atlas Mnemosyne de Warburg ou mesmo os vídeos de Viola.

O atlas, ao contrário da memória histórica, assemelha-se a uma "estação de despolarização e repolarização" (Agamben, 2010, p. 37) - 'dinamogramas desconexos' para Warburg - similar ao processo de dar vida a imagens do passado que pareciam esquecidas, mas que realmente sobreviveram suspensas e passam a ser visíveis durante o estado de sonolência e depois ao despertar. Essa dinâmica entre imagem e signo, batizada de 'movimento pendular' trata da persistência da imagem ausente por meio dos conteúdos.

Agamben retoma, então, o tema central das Ninfas, esmiuçando seus atributos dando voz aos escritos seminais sobre o assunto, entre eles o tratado de Paracelso De ninphis, silphis, pigmeis et salamandris et caeteris spiritibus, ligando cada um destes seres aos quatro elementos, a saber (seguindo a ordem do título): água, ar, terra e fogo. Entre eles, somente a ninfa se apresenta com aparência humana, porém, como os outros, não possui alma e, consequentemente, sobre essas criaturas pode-se dizer que não são nem homens nem animais e tampouco propriamente espíritos. Paracelso resume a compaixão que nutre por elas procurando defini-las como "seres humanos que, sem dúvida, morrem como os animais, caminham como os espíritos e comem e bebem como os homens" (2010, p. 41). Igualmente, descreve os fatores da similaridade com os humanos, tanto no caráter como na organização e modo de vida, fazendo questão de assinalar que "fazem uso da razão e governam suas comunidades com justiça e prudência" (2010, p. 42).

Uma distinção marcante das ninfas para as outras criaturas elementares reside no fato de que "podem receber uma alma, caso se unam sexualmente a um 
homem e com ele engendram um filho" (Agamben, 2010, p. 42) tradição que conduz a outra mais antiga, sobre a ligação indissolúvel delas com o signo de Vènus e do amor. No entanto, o responsável por associar a ninfa ao amor foi Giovanni Boccaccio, poeta e crítico literário italiano, quando fez desses seres a figura central de suas prosas e poesias amorosas e, mais ainda, quando compôs a Comedia delle ninfe fiorentine (1341). Pode-se dizer que Boccaccio é precursor do humanismo renascentista quando introduz o problema moderno da relação entre a vida e a poesia. Por outro lado, coube também a Boccaccio opor as mulheres às Musas na célebre frase "é verdade que todas são mulheres, mas não mijam" (2010, p. 47), definindo a ninfa como

[...] a dimensão poética na qual as imagens haveriam de coincidir com as mulheres reais, a 'ninfa florentina' está em vias de dividir-se entre suas polaridades, de um lado demasiado viva e animada, sem que o poeta alcance e the confira uma vida unitária. (Agamben, 2010, p.47)

Persiste, porém, a imaginação, o "princípio definidor da espécie humana" (Agamben, 2010, p. 49) descoberto pela filosofia medieval, que se posiciona no "limite entre o corpóreo e o incorpóreo, o individual e o comum, a sensação e o pensamento" (2010, p. 49), já a literatura moderna nasce da cisão dessa imago medieval, rompendo com a conjunção assegurada pela poesia amorosa, entre o mundo sensível e o racional (Idem). Warburg, na construção do atlas recorre às imagens da humanidade ocidental, quando a ninfa "assume a ambígua herança da imagem, mas a desloca para um plano histórico e coletivo" (2010, p. 50). Neste ponto suas idéias coincidem com o princípio benjaminiano de que existe vida naquilo que é história e, embora, habitualmente atribuamos vida apenas ao corpo biológico, ninfal "é uma vida puramente histórica" (2010, p. 51). Alinhavando tais conceitos, Agamben escreve:

A história da humanidade é sempre história de fantasmas e imagens, porque é na imaginação que acontece a fratura entre o individual e o impessoal, o múltiplo e o único, o sensível e o inteligível e, ao mesmo tempo, a tarefa de sua dialética recomposição. $(2010$, p. 53) 


\section{REFERÊNCIAS}

\section{Bibliografia citada}

Agamben, Giorgio. Ninfas. Tradução Antonio Gimeno Cuspinera. Valencia, Espanha: Imprenta Kadmos; 2010.

Benjamin, Walter. La obra de arte en la época de su reproductibilidad técnicaIn: Benjamin, Walter. Discursos interrumpidos, 3v. Análises Jesus Aguirre. Vol.1. Buenos Aires, Argentina: Aguilar/Altea/Taurus/Alfaguara S.A. de Ediciones; 1989.

Krausz, Luis S. As Musas: poesia e divindade na Grécia arcaica. São Paulo: EDUSP; 2007.

\section{Fontes eletrônicas e sites}

Aby Warburg e os arquivos da memória. Acesso em 12/08/1019. Disponível em: http://www.educ.fc.ul.pt/hyper/resources/aguerreiro-pwarburg/.

Bill Viola at Work: Making the Passions Videos. Acesso em 22/08/1019. Disponível em: https://www.youtube.com/watch?v=GQuSYsFMMt4.

Dicionário de filosofia. Acesso em 12/08/1019. Disponível em: https://sites.google.com/view/sbgdicionariodefilosofia/redu\%C3\%A7\%C 3\%A3o-eid\%C3\%A9tica. 